\title{
DESAFIOS QUE OS ESTUDANTES NATIVOS DIGITAIS LEVAM PARA A ESCOLA: RELATOS DE PROFESSORES
}

\author{
CHALLENGES NATIVE DIGITAL STUDENTS TAKE TO SCHOOL: TEACHER \\ REPORTS
}

\author{
Jorge Alberto dos Santos ${ }^{1}$
}

RESUMO: Partindo do pressuposto que a TIC - Tecnologia da Informação de Comunicação está presente no cotidiano da sociedade moderna e considerando que esta pode ser percebida no ambiente escolar, um questionamento emergiu: Quais os desafios que estudantes nativos digitais levam para escola dada a perspectiva do professor? Com base no momento atual em que as tecnologias digitais avançam em direção a sociedade contemporânea, consideramos que as ferramentas e os serviços oferecidos pela TIC para o contexto escolar merecem maior atenção e pesquisa. Assim, foram verificadas a evolução de história da informática e TICs, o papel do professor no contexto escolar, os estudantes nativos digitais bem como o uso da internet nas escolas, para dar um panorama de que como estes elementos estão se organizando no espaço educacional. Para isso, foram feitas pesquisas acadêmicas em livros, artigos científicos e aplicação de questionário para professores de uma escola pública do Distrito Federal com o foco de investigar os possíveis desafios que os estudantes nativos digitais levam para a escola. Foram elaboradas três categorias de análise: ferramentas de TIC, provedor de serviços e a aperfeiçoamento. Os resultados alcançados com a pesquisa realizada permitiram identificar que existem desafios a serem superados pelos docentes em suas atividades pedagógicas, dentre eles o de assumirem o papel de "filtro" das informações acessadas a partir dos dispositivos tecnológicos dos alunos ou da própria escola no ambiente de ensino. Finalmente, entendo a necessidade de uma melhor atenção do professor para o uso dos recursos de TIC na escola.

Palavras-chave: TIC. Estudantes nativos digitais. Papel do professor.

ABSTRACT: Based on the assumption that ICT - Information Communication Technology is present in the daily life of modern society and considering that it can be perceived in the school environment, a questioning emerged: What are the challenges that digital native

\footnotetext{
${ }^{1}$ Professor Mestre de Graduação e Pós-Graduação na modalidade presencial e EAD em Faculdades Particulares de Brasília e Centro Universitário, Pós-Graduado em Governança de TI, Graduado em Administração de Empresas. Instrutor de Cursos Técnicos de Tecnologia da Informação e Comunicação. Palestrante em eventos sobre de Governança de TI. Atuante como Gerente de Projetos de TI certificado PMP e Princez, Consultor de Governança de TI em uma empresa no ramo de tecnologia da informação. Vivência na área de Administração de Empresas, Gestão de Processos de TI, Gestão de Equipe, Desenvolvimento Profissional, Planejamento Estratégico e Mapeamento e Melhoria de Processos. Experiência e atuação na área de Infraestrutura de TI em várias organizações do mercado de Brasília. Pesquisador e incentivador de metodologias para gestão humanizada de pessoas e de ferramentas tecnológicas para apoio ao ensino.E-mail: ntjorge@gmail.com
} 
students take to school given to perspective of the teacher? Based on the current moment when digital technologies are moving towards contemporary society, we believe that the tools and services offered by ICT for the school context deserve greater attention and research. Thus, the evolution of the history of informatics and ICTs, the role of the teacher in the school context, the native digital students as well as the use of the internet in schools, were verified to give an overview of how these elements are organizing in the educational space. For this, academic researches in books, scientific articles and interviews with teachers of a public school of the Federal District were made with the focus of investigating the possible challenges that the native digital students take to the school. Three categories of analysis were developed: ICT tools, service provider and improvement. The results obtained with the research made it possible to identify that there are challenges to be overcome by the teachers in their pedagogical activities, among them that of assuming the role of "filtering" the information accessed from the technological devices of the students or from the school itself in the environment of teaching. Finally, I understand the need for better teacher attention to the use of ICT resources in school.

Keywords: TIC. Native digital students. Teacher role.

\section{INTRODUÇÃO}

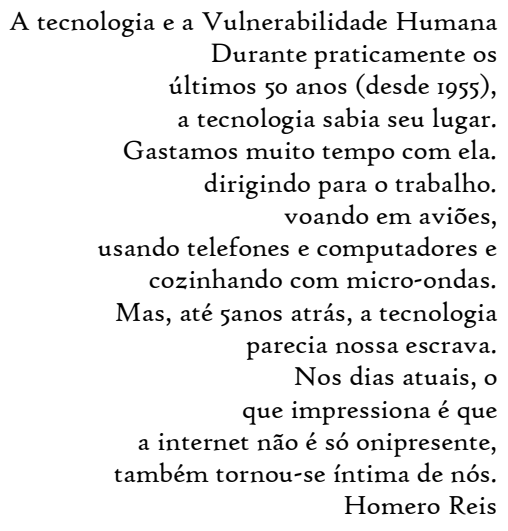

Relato o texto "A tecnologia e a vulnerabilidade humana" do professor (REIS, 2004) como parte inicial do meu trabalho por motivos diversos. Tendo sido escrito por um grande mestre em maio de 2004, o texto traz uma riqueza de análise quando demonstra que a tecnologia entrou em nosso cotidiano. $\mathrm{O}$ autor apresenta a ideia de que o ser humano domina a tecnologia, afirma também que a TIC se tornou íntima de todos nós, soando como um elemento enraizado em nosso cotidiano. Eu estou de acordo com a afirmação do autor de que a TIC se tornou íntima de nós, e tomando por base este pensamento surgiram as seguintes indagações, que servirão de base para iniciar as reflexões do tema do presente trabalho: A escola precisa se reinventar e se adaptar à nova forma de sociedade? A instituição escolar da 
atualidade está preparada para atender às necessidades da sociedade moderna? Os professores devem se adaptar às necessidades dos estudantes nativos digitais?

Com as modificações culturais, sociais e educacionais identificadas na década de 1990 e tendo em vista que as pessoas da sociedade moderna buscam um ambiente social mais conectado, emerge uma categoria de estudante que é denominado de nativo digital. Por estudante nativo digital, entende-se o estudante que nasceu em uma época em que a tecnologia da informação e comunicação é presente e predominante no cotidiano social. É interessante repensar a forma como a escola pode trabalhar com ferramentas da tecnologia da informação e comunicação tais como: Facebook, Twitter, Google, Wikipedia, Chat, E-mail, Fórum de discussão, Redes sociais, Vídeos, Podcast, Jogos educativos e Material multimídia.

Ao assumir a ideia de que a tecnologia da informação e comunicação faz parte do cotidiano dos estudantes nativos digitais e, partindo do pressuposto de que a TIC está presente na vida das pessoas da sociedade contemporânea, desse modo torna-se interessante refletir os desafios que os estudantes nativos digitais levam para a escola dada a perspectiva do professor. História da Informática

Na visão de Pinochet (2014):

É importante conhecermos a história da informática para entendermos como evoluímos, onde estamos e para onde caminhamos com base na evolução de hardware, de software, e de redes, que favoreceram processos de evolução e revolução nas comunicações, e na forma como vivemos em um mundo em constantes transformações. (PINOCHET, 2014, p. 89).

Para entender o significado e o uso da TIC - Tecnologia da Informação e Comunicação é pertinente ter uma compreensão do que se trata o termo "tecnologia". Na visão de Pinochet (2014, p. I); ele tem sua "origem grega e é formado por duas palavras: tekne, que significa técnica, e logos que significa conjunto dos saberes". As ferramentas tecnológicas conseguem interagir com várias áreas de conhecimento tais como: a administração, biologia, física, química, psicologia, pedagogia.

Para Pinochet (2014), é inegável e observável que as atividades desenvolvidas pelo ser humano são modificadas pela presença da tecnologia. Verifica-se que a tecnologia vem modificando alguns aspectos culturais, socioeconômicos, educacionais, na área da saúde, no ambiente das organizações, nas relações de trabalho, na estrutura dos mecanismos financeiros e principalmente na forma como as pessoas se relacionam e interagem umas com as outras. 
A tecnologia da informação pode assumir uma variedade de funções e finalidades específicas no âmbito da sociedade. Uma finalidade específica está relacionada com a disseminação da informação.

Na perspectiva de Pinochet (2014), a TIC se aplica:

No estudo, no desenvolvimento e, na prática de sistemas de computador, especialmente no que diz respeito à união de software, hardware e peopleware, de modo que podem rapidamente definir sua atividade na evolução da computação apoiada por redes de comunicação. (PINOCHET, 20I4, p. 2).

Pinochet (2014) relata que "o fundamento da sociedade da informação está associado às novas tecnologias da informação e comunicação". Ele menciona que a sociedade da informação estaria atrelada às TICs, e o teórico Castells (2002) complementa a afirmação ao dizer em sua obra que há uma convergência de tecnologias para integrar vários sistemas computacionais. Colaborando com o pensamento de integração, Silva (2004) relata que no ambiente da era da informação e de uma sociedade em transformações constantes, a escola poderia pensar na possibilidade de acompanhar as mudanças contínuas para não ficar parada no tempo.

Prensky (200I) afirma que os nativos digitais "são acostumados a receber a informação muito rápida". Busca-se observar que, no contraponto do uso das TICs como uma possível fonte de apoio transformador aos vários processos educacionais, existem questões que merecem atenção, dentre elas a disseminação das imagens pelo uso dos aparelhos tecnológicos, sejam eles: TV, aparelho celular, computadores, notebooks, tablets, máquina fotográfica, scanner, dentre outros.

\section{O que são TICs?}

A comunicação é um componente importante no contexto das empresas, das escolas, das pessoas e da sociedade de uma maneira geral. A tecnologia da informação sofreu outra modificação ao ampliar sua área de atuação no sentido de incorporar a comunicação em sua definição. Nasce, assim, a TIC - Tecnologia da Informação e Comunicação. Pinochet (2014) afirma o seguinte:

O processo de comunicação é também responsável por avanços tecnológicos. Devido à troca de mensagens, informações e consequentemente troca de experiências, grandes descobertas 
científicas foram realizadas. A comunicação é considerada algo de extrema complexidade, uma vez que existem atualmente várias formas e recursos tecnológicos para a realização dessa atividade. (PINOCHET, 20I4, p. 2).

Na visão de Belloni (1998) é possível entender o conceito de TICs pela presença de suas características que se traduzem em: maior acessibilidade, virtualidade, simulação e uma série de informações.

Laudon e Laudon (2004) apontam que tecnologia da informação é um conjunto formado por hardware e software e serve para coletar, processar, armazenar e disseminar informações. A disseminação da informação é um ponto relevante da comunicação massiva que a TIC permite realizar.

A escola hoje

Minha percepção de escola na sociedade contemporânea está ancorada nas visões dos autores SAVIANI (2012) e COIMBRA (1989) que irei resumir nos próximos parágrafos. Saviani (2012, p. 22) relata que a escola assume o papel de aparelho ideológico do Estado. Para o autor:

O conceito de aparelho ideológico do estado deriva da tese segundo a qual a ideologia tem uma existência material. Isso significa dizer que a ideologia existe sempre radicada em práticas materiais reguladas por rituais materiais definidos por instituições materiais. Em suma, a ideologia materializa-se em aparelhos: Os Aparelhos Ideológicos do Estado. (SAVIANI, 2012, p. 22).

Na visão de Saviani (2012, p. 22):

Uma grande parte (operários e camponeses) cumpre a escolaridade básica e é introduzida no processo produtivo. Outros avançam no processo de escolarização, mas acabam por interrompê-lo passando a integrar os quadros médios, os "pequenos-burgueses de toda espécie." (SAVIANI, 2012, p. 22).

Corroborando a ideia do teórico Saviani segundo a qual instituição escolar serve ao sistema financeiro vigente e as classes sociais "superiores", a autora COIMBRA (1989) detalha um pouco mais os aspectos históricos da escola:

É a partir do século XVII que vemos a Escola surgindo como instituição, nos moldes em que a conhecemos atualmente. Portanto, o aparecimento desta instituição está visceralmente ligado ao desenvolvimento do capitalismo. Com a Revolução Industrial, a partir de 1750, sentiu-se a necessidade de um número maior de pessoas que soubessem pelo menos ler, escrever e contar. Pessoas essas que seriam jogadas nas nascentes indústrias, fornecendo mão-de-obra para o manejo das máquinas. Por outro lado, a burguesia já no poder percebeu também a necessidade de "socializar" e 
"educar" a massa trabalhadora existente nos grandes centros urbanos, para formá-los como "bons" cidadãos e trabalhadores disciplinados. Com isso, vemos a Escola surgindo com claras funções: inculcar os valores, hábitos e normas da classe que domina, ou seja, inculcar a ideologia burguesa e, com isso, mostrar a cada lugar que deve ocupar na sociedade, segundo sua origem de classe. (COIMBRA, p.I4-16, 1989).

Há, pois um elo entre a escola mercantilista contemporânea e a tecnologia da informação e comunicação no ambiente escolar.

TICs no ambiente escolar

Na percepção de Moran (2007), as escolas, em um ritmo acelerado, estão cada vez mais no processo de virtualizar seus serviços. Na visão do autor, trata-se de um caminho sem volta e, nesse sentido, existe a probabilidade de que a escola e o docente passem por esse enfrentamento estrutural. $\mathrm{O}$ docente é uma das partes relevantes no contexto escolar e pode ser auxiliado e capacitado com o uso do recurso de ensino à distância, a chamada EaD. O termo EaD possui muitas definições, segundo vários autores. Utilizarei duas definições, uma de Riano (1997) na qual o autor afirma que se trata da:

Relação, professor aluno ou ensino-aprendizagem mediada pedagogicamente e mediatizada por diversos materiais instrucionais e pela orientação tutorial. Isto é válido tanto para ambientes pedagógicos tradicionais como para aqueles que usam as novas tecnologias. (RIANO, I997, p. 20).

Há outra definição para EaD da própria legislação brasileira, Decreto 5.622 de I9 de dezembro de 2005, que define Educação a Distância como sendo uma:

Modalidade educacional na qual a mediação didático-pedagógica nos processos de ensino e aprendizagem ocorre com a utilização de meios e tecnologias de informação e comunicação, com estudantes e professores desenvolvendo atividades educativas em lugares ou tempos diversos. (BRASIL, DECRETO 5.622 de i9 de DEZEMBRO de 2005).

Muitas escolas possuem ferramentas tecnológicas em seus ambientes, sendo algumas delas: TV, vídeo, DVD, 'internet', computadores e outros dispositivos, e serviços ligados à tecnologia da informação e comunicação. As novas tecnologias podem servir como ferramenta para ampliar nas escolas o processo de comunicação entre os envolvidos: professores e alunos. Kenski (2003) relata que as TICs não restringem sua participação no ambiente escolar agregando novas tecnologias, mas também permitindo novas possibilidades de pesquisas acadêmicas e conteúdos educacionais. 
$\mathrm{Na}$ visão de esteve (1999), os professores estão em situação delicada frente às transformações ocorridas na escola com a presença da tecnologia da informação. A evolução da tecnologia da informação e comunicação, e seu respectivo uso nas escolas podem provocar no ambiente de ensino questionamentos acerca da real capacidade do corpo docente no manuseio e domínio das ferramentas computacionais.

$\mathrm{Na}$ visão de Amigues (2004, p. 42):

A atividade do professor também busca seus meios de agir nas técnicas profissionais que se constituíram no decorrer da história da escola e do ofício do professor. Em outros termos, a atividade não é a de um indivíduo destituído de ferramenta, socialmente isolado e dissociado da história; pelo contrário, ela é socialmente situada e constantemente mediada por objetos que constituem um sistema. (AMIGUES, 2004, p. 42).

\section{O papel do professor no ambiente escolar}

Toda discussão apresentada neste capítulo em relação ao papel do professor no ambiente escolar tem o foco da escola com traços mercantis. Não concordo com a idéia de tipificar os professores e nem tampouco fazer uma classificação dos docentes. Os autores Tunes, Tacca e Bartholo (2005) apresentam um texto em que criticam os possíveis papéis que muitos buscam enquadrar os professores.

Para Tunes, Tacca e Bartholo (2005):

Há muito tempo e para muitos, ao professor caberia o papel de jardineiro. Fertiliza-se o solo, semeia-se, mantém-se o solo úmido, protege-se o broto de pragas e ervas daninhas para que possa crescer saudável e mostrar seus frutos. Não se interfere na planta. É necessário apenas protegê-la das adversidades para que possa desenvolver em plenitude suas potencialidades naturais. Nada há o que deva limitar a semente. Essa é a metáfora que se pode fazer da educação permissiva, com excesso de relaxamento e indulgência. Outra visão, também compartilhada por muitos, admite o professor como uma espécie de escultor. A partir da pedra bruta, delinear e moldar formas reconhecíveis, estritamente conforme o plano gestado na imaginação do escultor. É claro que o material de que é feita a pedra bruta impõe algumas condições de limites para a ação do escultor. Limites estes, contudo, muito mais circunscritos aos instrumentos a utilizar do que propriamente ao que se pretende esculpir. $\mathrm{O}$ que importa, pois, é o que foi planejado; o projeto que dirige e justifica todas as ações e os meios a serem empregados. Nada mais há que deva impor restrições ao plano do escultor. (TUNES, TACCA E BARTHOLO, 2005).

Illich (1985, p. 45), apesar de tecer críticas a tipologia de docentes, apresenta três possíveis papéis do professor, sendo eles: 
O professor-guardião atua como mestre de cerimônias que dirige seus alunos através de um ritual labirinticamente traçado. É árbitro da observância das normas e ministra as intrincadas rubricas de iniciação à vida. No melhor dos casos, coloca os fundamentos para a aquisição de alguma habilidade, à semelhança daquela que os professores possuem. Sem pretensões de conduzir a uma aprendizagem profunda, treina seus alunos em algumas rotinas básicas.

O professor-moralista substitui os pais, Deus ou o Estado. Doutrina os alunos sobre o que é certo ou o que é falso, não apenas na escola, mas também na grande sociedade. Está in loco parentis para um dos alunos e, assim, garante que todos se sintam crianças da mesma nação.

$\mathrm{O}$ professor-terapeuta julga-se autorizado a investigar a vida particular de seus alunos de modo a ajudá-los a tornarem-se pessoas. Quando esta função é exercida por um guardião ou pregador, normalmente significa que persuade o aluno a domesticar sua visão do verdadeiro e seu senso do que é correto. (ILLICH, 1985, p. 45).

\section{Estudantes nativos digitais}

Prensky (200I) relata que os nativos digitais desconhecem o mundo sem a presença de tecnologias tais como: aparelhos de celular inteligentes, videogames, redes sociais e navegadores. Os nativos digitais fazem parte de uma revolução que acontece cadenciadamente. Os nativos digitais já nascem em um ambiente em que a presença da TV é marcante e massiva.

Segundo a visão de Prensky (200I), os nativos digitais nasceram e vivem em meio a uma quantidade imensa de informações e eles costumam receber essas informações de maneira rápida, natural e contínua. Por isso, adoram trabalhar com processos em paralelo, ou seja, estão adaptados para fazer várias coisas ao mesmo tempo. Preferem trabalhar em redes computacionais e sociais do que separados, daí o fato das "redes sociais" surgirem como um fenômeno de aceitação pelos nativos digitais. As mudanças provocadas pelas TICs estão ocorrendo em grande parte do Brasil e merecem uma especial atenção, principalmente por parte da instituição escolar.

Os estudantes nativos digitais se percebem como parte do mundo global e vão buscar os componentes tecnológicos no ambiente das escolas.

Os nativos digitais são extremamente criativos. É impossível dizer se são mais ou menos criativos do que as gerações anteriores. Eles se expressam criativamente de formas diferentes daquelas que seus pais usavam quando tinham a mesma idade. Muitos nativos digitais percebem que a informação é maleável, algo que podem controlar e reconfigurar de maneiras novas e interessantes. Eles conseguem ter certo controle sem precedentes sobre seu 
ambiente cultural, quer tenham ou não percepção disso. (PALFREY \& GASSER, 20II, p. 16).

\section{A internet nas escolas}

O assunto internet nas escolas pode ser divivido abordando os seguintes eixos:

\section{Uma ferramenta de pesquisa}

No começo do século XXI a internet se tornou um componente tão importante para a sociedade moderna que muitas organizações possuem seus negócios estruturados nos serviços que a grande rede de computadores fornece. É possível comparar a essencialidade da internet com a importância da energia elétrica, item igualmente relevante para grande parte dos indivíduos.

Para Pinochet (2014, p. I50, apud Grillo, 2007) internet é um “conjunto de tecnologias diversas e conectadas, e não como um artefato único.” Um dos sentidos das empresas e pessoas usarem a internet é a conectividade, ou seja, existe uma busca pela constante conexão em que cada um assume seu próprio papel e identidade, que se denomina Avatar.

\section{Espaço virtual para apoiar as tarefas educacionais}

Ao observar o cenário escolar na sociedade moderna, é importante analisar que as tarefas educacionais não são as mesmas de épocas remotas. É preciso que aluno e professor formem uma parceria de colaboração mútua, para que as tarefas realizadas no âmbito escolar tenham resultados satisfatórios.

Algumas tarefas educacionais que a internet pode auxiliar:

- Acesso a e-mail da instituição escolar;

- Ingressar em salas de bate-papo educacionais e/ou fóruns de ensino;

- Download de apostilas e/ou material de estudo;

- Praticar jogos educativos online entre outros.

\section{Troca de informações}

De certa forma, o "terreno virtual" chamado de internet pode permitir para a escola a presença de uma gama considerável de informação. Para os atores principais da educação, professores e alunos, o uso da informação entregue pela internet requer a aplicação de filtros. 
Ou seja, não basta acessar a internet e executar a busca por informações de um determinado assunto, antes, é preciso verificar - aplicar filtros - as fontes que são apresentadas nos resultados das pesquisas realizadas.

Em decorrência da busca das informações no ambiente da internet, o novo formato de leitura aparece como um grande desafio para determinados grupos de professores. Segundo Santos (2003) "a internet não apenas inova o texto e seu modo de apresentação e leitura, como também propõe novos gêneros de textos e novas modalidades de leitura."

\section{Plataforma de comunicação}

A presença da internet no espaço escolar, além de ampliar a busca por informações, estabelece e amplifica novas possibilidades de comunicação entre professores e alunos. É importante entender que no atual estágio que as TICs se encontram e com o suporte da internet, caminha-se para que se tenham formas de comunicação audiovisual. Moran (20oI) menciona:

Mas a qualquer momento você poderá ver e ouvir facilmente os outros, e a um custo barato. Isso é algo que até agora só as pessoas da televisão fazem, repórteres e apresentadores, vendo-se e conversando ao vivo de diferentes países. Com a Internet e a velocidade isso vai ser relativamente fácil e barato. (MORAN, 200I, p. 3).

\section{Mídia que modifica as práticas pedagógicas do professor}

Ao demonstrar o uso da internet no ambiente escolar em quatro grandes eixos, ou seja, enquanto ferramenta de pesquisa, espaço virtual para apoiar as tarefas educacionais, como troca de informações e sendo uma plataforma de comunicação, é relevante afirmar que a internet se tornou, então, uma possível mídia que modifica as práticas pedagógicas do docente.

Para acontecer a modificação das práticas pedagógicas, um passo importante é integrar as tecnologias ao cotidiano da escola. Moran (200I, p. 14) afirma ser preciso “[...] integrar as tecnologias com a vida o tempo todo, o real e o virtual. Precisamos aprender a integrar tudo, num olhar abrangente [...].”

A maioria dos professores que, até então, não interagia de maneira intensa com as ferramentas da tecnologia da informação e comunicação, agora, se situa no entremeio de uma pressão exercida por parte dos alunos e da própria instituição escolar para que haja a incorporação da internet e outras ferramentas das TICs nas práticas pedagógicas. 
$\mathrm{O}$ uso da internet permite modificar a forma como projetos de educação são conduzidos e estruturados, sendo possível para o docente manter uma supervisão mais precisa em relação aos resultados desejados, bem como acompanhar as atividades pedagógicas desenvolvidas pelo aluno.

\section{A trilha metodológica da pesquisa}

Após estabelecer os objetivos do trabalho e ter apresentado a base teórica, foi momento de traçar o "como fazer". Face à dificuldade de agenda dos professores escolhidos devido aos compromissos diários de ministrarem suas aulas, a pesquisa durou cerca de dois meses e serviu para coletar as respostas dos docentes e, principalmente, suas percepções do uso de recursos das TICs na instituição escolar.

Para escolher os procedimentos e instrumentos e alcançar os objetivos pretendidos neste trabalho científico, foi necessária uma cuidadosa análise. Optei por aplicar um questionário com perguntas fechadas e abertas para um grupo de dez professores de uma escola pública da Secretaria de Estado de Educação do Distrito Federal. O questionário utilizado teve dezessete perguntas e a aplicação foi realizada individualmente. Os docentes foram escolhidos independentemente de gênero, todos com grau de escolarização de nível superior, com faixa etária entre trinta e cinco e quarenta e cinco anos. A escolha da escola foi por razões de ordem prática de localização e acesso.

\section{Análise dos dados}

As respostas foram organizadas em função das próprias perguntas em categorias com foco no objetivo da pesquisa. Nos trechos das respostas dos docentes, os professores foram identificados com $\mathrm{P}_{1}, \mathrm{P}_{2}, \mathrm{P}_{3}$ e, assim, sucessivamente.

Em relação à primeira pergunta um, sem categoria, buscou-se saber como é o conhecimento do professor em relação ao uso de computador e internet.

Do total de respostas capturadas cerca de 50\% (cinquenta por cento) dos pesquisados possuem nível intermediário de conhecimento, 20\% (vinte por cento) nível avançado e 30\% nível básico de conhecimento em relação ao uso de computador e internet, conforme Figura I. 
Figura r: Como é o seu conhecimento em relação ao uso de computador e internet?

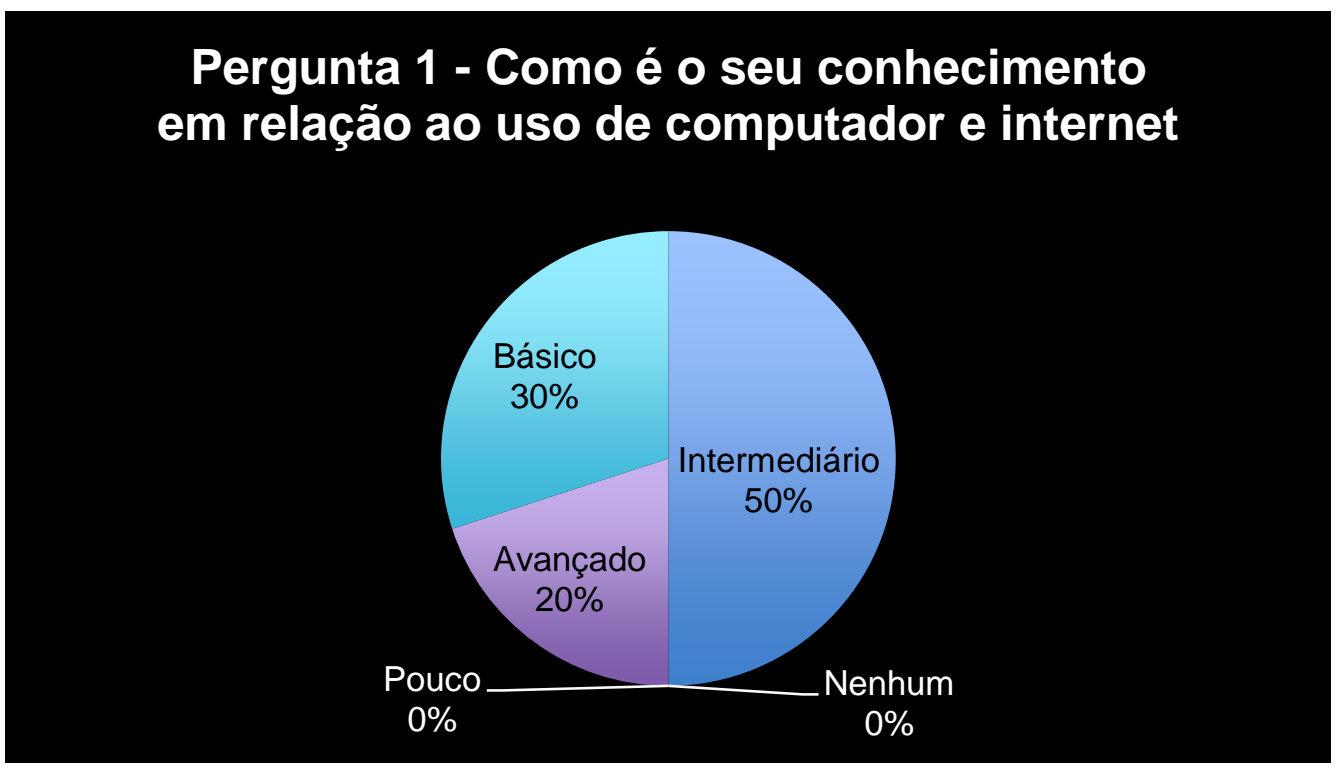

Ao analisar a primeira questão apresentada em relação ao conhecimento do uso de computador e internet, depreende-se que se somarmos o nível intermediário e avançado, obtem-se o valor de $70 \%$ (setenta por cento) dos pesquisados com nível considerável de conhecimento em relação às tecnologias perguntadas. Do total pesquisado, apenas 30\% possuem conhecimentos básicos em relação ao uso de computador e internet.

A categoria ferramenta de TI foi elaborada pensando em ter a noção da forma como os professores definem TIC e estudantes digitais e de que maneira eles observam e usam os recursos tecnológicos em suas atividades rotineiras. Assim, na pergunta dois buscou-se identificar o que eles entendiam por Tecnologia da Informação e Comunicação - TICs. O que pude constatar, apesar de 70\% (setenta por cento) - conforme pergunta um - responderam saber usar computador e internet, é que não há um consenso em relação à definição do termo TIC. Do total dos pesquisados, I0o\% (cem por cento) dos professores deram respostas incompletas em relação aos conceitos apresentados neste trabalho, sendo possível identificar divergências nas definições de TIC nas respostas coletadas dos pesquisados $\mathrm{P}_{1}, \mathrm{P}_{2}, \mathrm{P}_{3}, \mathrm{P}_{4}, \mathrm{P}_{5}$ a seguir:

É uma área da informática que visa contribuir para a comunicação por meio do uso da tecnologia de forma rápida e eficaz de maneira a evitar o retrabalho gerando uma maior dinâmica para as atividades ( $\mathrm{PI})$. 
São meios ou recursos que cada vez mais mudam as formas com as quais nos comunicamos. Podemos armazenar, compartilhar, produzir as informações por meio das TICs $\left(\mathrm{P}_{2}\right)$.

São todas as tecnologias que podem ser utilizadas para geração, transformação $e$ troca de informações, e que também são meios de comunicação entre dispositivos eletrônicos e pessoas $\left(P_{3}\right)$.

É a maneira como a tecnologia resolve problemas de comunicação entre as pessoas $\left(\mathrm{P}_{4}\right)$.

É um sistema que busca controlar os mecanismos de informática da empresa e tem por objetivo apoiar as unidades de negócios da empresa ( $\left.\mathrm{P}_{5}\right)$.

Nos relatos dos pesquisados não foi constatada uma resposta que contivesse a presença de hardware e software no contexto do conceito.

A pergunta três, diz respeito à percepção do uso da TIC no contexto escolar. O relato do professor $\mathrm{P}_{4}$, resume as demais respostas:

As TIC's são importantes, pois facilitam a troca de informação desde que utilizadas para esse fim contribuindo para que mais alunos possam trocar informações $e$ aprender $\left(\mathrm{P}_{4}\right)$.

De acordo com os dados coletados na pergunta três, I0o\% (cem por cento) dos pesquisados, responderam que a tecnologia da informação e comunicação pode ser importante em algum aspecto no contexto escolar.

Do total dos participantes, 30\% (trinta por cento) deram respostas que se aproximam da definição do autor Prensky. Já 70\% (setenta por cento) apresentaram definições distorcidas do conceito de estudantes nativos digitais e estão representados sintetizadamente nos relatos dos professores $\mathrm{P}_{7}, \mathrm{P}_{8}, \mathrm{P}_{9}$ :

Salvo engano "Nativo Digital" é um termo norte americano usado para designar uma geração dos nascidos na era da informação $\left(\mathrm{P}_{7}\right)$.

São aqueles que já estão inseridos neste contexto, ou seja, já nasceram dentro dessa onda tecnológica (P8).

Conheço muito pouco do termo. Parece-me que são estudantes que usam internet (P9).

Conforme se percebe nos relatos dos professores - $\mathrm{P}_{7}$ e $\mathrm{P}_{9}$ - , é possível depreender que ambos não possuem noção acerca da definição de nativos digitais. $\mathrm{O}$ docente $\mathrm{P}_{7}$ inclusive 
no termo “salvo engano" deixa a entender que há dúvidas em seu relato. Já o professor P9 relata diretamente que conhece pouco o termo estudante nativo digital.

$\mathrm{Na}$ pergunta quatro buscou identificar se os docentes acreditam que os recursos da tecnologia da informação e comunicação podem colaborar com os trabalhos acadêmicos no ambiente escolar. Do total dos participantes I0o\% (cem por cento), ou seja, os dez professores responderam de maneira positiva. Os relatos dos professores $\mathrm{P}_{1}, \mathrm{P}_{2}$ e $\mathrm{P}_{3}$ representam o resumo das respostas de todos os pesquisados:

Sim, pois tende a contribuir para que os alunos tenham uma melhor oportunidade de acesso à informação que é global....realizando trabalhos com diversas fontes de pesquisa $\left(P_{I}\right)$.

Não tenho dúvidas disso. Se bem trabalhadas, essas tecnologias podem colaborar de maneira inequívoca com a educação ( $\left.\mathrm{P}_{2}\right)$.

São formas de pesquisa bastante ágeis, entretanto é necessário formar os estudantes para o uso destas tecnologias $\left(P_{3}\right)$.

Na pergunta seis objetivou-se identificar se a escola utiliza algum recurso tecnológico tais como: computadores, internet, redes sociais, whatszap ou blogs. O relato do professor Pio representa de maneira geral os demais relatos:

A escola utiliza tais recursos na elaboração de relatórios, pesquisas de atividades para os alunos (copia e cola) e na parte burocrática (vida do funcionário, envio de documentos). O WhatsApp é utilizado para se criar um grupo administrativo e pedagógico dos funcionários da escola que basicamente serve para envios de informes da direção que se perdem nas mensagens de bom dia, boa tarde, boa noite, bíblicas e autoajuda. Na sala de aula se utiliza pouco, na minha opinião, os recursos do computador e quando utilizados são "pedagogizados", por exemplo: slides do Power Point, vídeos educativos... enfim, não diferem muito da realidade de uma aula considerada tradicional (Pıo).

Do total dos participantes, I0o\% (cem por cento) dos docentes relataram que a escola utiliza algum tipo de recurso de informática. Destaco que o relato do professor Pio chama atenção pelo fato de mencionar que os recursos de TI não são utilizados com finalidade acadêmica. No contexto da resposta do entrevistado Pıo, os professores poderiam assumir o papel de "instrutor" para que os alunos aprendam a executar seus próprios filtros de conteúdos. A idéia seria a de que nem os representantes da direção da instituição escolar, nem os próprios docentes proibiriam a entrada ou uso dos dispositivos de TIC na escola, mas ensinariam os alunos a filtrar o que diz respeito e o que não diz respeito à pesquisa acadêmica e/ou trabalhos escolares. 
A questão de restrição, proibição e controle de recursos de TI, pode ser percebida no relato do professor $\mathrm{P}_{9}$, a seguir:

Sim. Na escola, temos computadores que não são utilizados, internet apenas para professores e celulares são proibidos em sala de aula $\left(P_{9}\right)$.

Enquanto o professor Pio ressaltou o uso das ferramentas de TIC para finalidade acadêmica, o docente $\mathrm{P}_{9}$ menciona a palavra "proibido". Concordo, analisando com a visão de professor acadêmico, que a tecnologia da informação e comunicação pode trazer contribuições positivas para o ambiente escolar, porém, com os devidos ajustes e controles. Posiciono-me para a visão de que é preciso aplicar filtros nos conteúdos acessados no ambiente escolar. $O$ professor passaria a executar mais um papel em sala de aula, o de instruir os alunos a como aplicar filtros nos conteúdos acessados.

No questionário aplicado referente à pergunta sete buscou-se analisar se as ferramentas de tecnologia da informação eram utilizadas na sala de aula. Entendo que, uma coisa são os recursos de TI na escola, outra coisa são os recursos de TI dentro de sala de aula. $\mathrm{O}$ relato do professor $\mathrm{P}_{4}$ apresenta possíveis indícios de um cenário que pode ser a realidade de sala de aula de outras escolas públicas:

Não utilizo Tics na minha sala de aula $\left(\mathrm{P}_{4}\right)$.

A exceção do professor $\mathrm{P}_{4}$, os demais professores, ou seja, 90\% (noventa por cento) dos pesquisados relataram respostas com teor próximo ao do docente P2:

Utilizo basicamente o computador, equipamento de data show e a internet para realizar pesquisas acadêmicas. Porém, é preciso que a escola passe por adaptações estruturais para receber outros dispositivos de informática ou, até mesmo, ampliar o uso dos que já estão em funcionamento $\left(\mathrm{P}_{2}\right)$.

Em relação ao uso de software em suas rotinas de estudo da pergunta oito, categoricamente $100 \%$ (cem por cento) dos professores participantes responderam que usam software nas rotinas de estudo.

Para embasar o uso da internet na escola, a pergunta dezesseis aborda se os alunos procuram serviços de internet, wi-fi e e-mail quando estão na escola. Partindo do pressuposto que a internet está presente no cotidiano dos estudantes nativos digitais, seria esperado que estes mesmos alunos procurassem os serviços de internet na escola. Do total dos dez participantes, I00\% (cem por cento) responderam que os alunos procuram os serviços 
mencionados na pergunta, não sendo possível identificar para qual finalidade, acadêmica ou para uso pessoal. Foi o que constatou-se nos relatos dos professores P6, P8, P9 e Pio que representam as respostas dos demais docentes:

Procuram, constantemente (P6).

Eles sempre buscam estar ligados á rede internacional internet (P8).

Sim, procuram constantemente a internet e um sinal de rede wi-fi $\left(P_{9}\right)$.

Sim, diariamente de aula buscam e muito (PIo).

$\mathrm{Na}$ questão dezessete que busca identificar se a inserção de recursos tecnológicos no ambiente escolar poderia propiciar a expansão de pesquisas acadêmicas e acesso às informações, todas as respostas coletadas podem ser resumidas no relato do professor Pı:

Sim. Vivemos na era da informação e temos que utilizar isso a nosso favor! (PI).

A segunda categoria é o provedor de serviços. Entendo que a escola se tornar uma provedora de serviços de TIC não deve ser algo trivial. Esta adaptação exigirá uma série de mudanças internas em termos de processos, pessoas e tecnologia. Para o autor Kenski (2003), não se trata apenas de adaptar o modelo de escola tradicional às novas ferramentas tecnológicas, é preciso transformar velhos hábitos das práticas educacionais. A escola assume o papel ativo e direcionador de promover os serviços de tecnologia da informação para os professores.

No questionário aplicado questão nove foi perguntado se escola oferece estrutura para o uso de tecnologias digitais. Para fins deste estudo, estrutura é o apoio técnico, operacional e a oferta de uma disposição física para que os serviços de tecnologia da informação sejam instalados e disponibilizados para o público final. As respostas dos professores $\mathrm{P}_{7}, \mathrm{P} 8, \mathrm{P}_{9}$ realçam bem o contexto e representam os relatos dos demais pesquisados:

Oferece alguns computadores e uma rede computacional. Porém, não tem funcionários para dar suporte ao serviço quando encontramos algum tipo de problema, ou seja, é preciso que a escola se adapte a esta nova realidade da sociedade $\left(\mathrm{P}_{7}\right)$.

Tem estrutura simples de serviço, mas não é muito eficiente. O equipamento de internet vive com problema e a escola não tem técnico para resolver. Às vezes, essa falta de internet me atrapalha em algumas aulas que eu já tinha programado usar a internet (P8). 
Oferecem coisas básicas, a internet é muito lenta $\left(\mathrm{P}_{9}\right)$.

A pergunta dez tem por objetivo identificar se a escola oferece treinamentos ou atualizações sobre temas de uso da tecnologia da informação e comunicação (Internet, Computador, Tablets, Recursos de Multimídia, Redes sociais, Whatsapp). O quadro analisado revela um ponto de atenção em que a maioria dos professores informou que a Instituição escolar não oferece nenhum tipo de treinamento em informática e não possui um programa preparado para trabalhar o aspecto. Do total dos dez professores participantes, I0o\% (cem por cento) responderam que desconhecem programas de treinamentos contínuos em informática. Nos trechos a seguir vemos os relatos dos professores $\mathrm{P}_{4}, \mathrm{P} 8, \mathrm{P}_{5}, \mathrm{P}_{1}$, que representam a maioria dos pesquisados:

Não oferece e não tem programas de treinamentos para informática. O que sei e aprendi foi em treinamentos externos que tive que pagar por eles $\left(\mathrm{P}_{4}\right)$.

Não existe um programa regular de capacitação para os professores utilizarem os recursos computacionais. (P8).

Parece que tem, mas não, é algo divulgado para todos, fiquei sabendo de alguns treinamentos porque vi um cartaz na sede da secretaria de educação do DF. Mas, não recebi nenhum comunicado oficial $\left(\mathrm{P}_{5}\right)$.

Não existe programa oficial de treinamento e capacitação para os docentes. Eu pelo menos desconheço qualquer ação por parte da Secretaria de Educação do Distrito Federal (PI).

A terceira e última categoria é o aperfeiçoamento. Quando criei esta categoria pensei inicialmente em analisar duas perspectivas: o aperfeiçoamento do professor e o/o aperfeiçoamento/melhoria dos processos educacionais. No questionário a questão onze indaga quanto à facilidade de acesso às redes sociais pelos alunos: qual sua visão sobre o uso das "Redes Sociais" como instrumento didático. Os relatos seguem na visão dos professores $\mathrm{P}_{1}, \mathrm{P}_{2}, \mathrm{P}_{3}$ e representam uma síntese das respostas de todos os pesquisados:

Na escola pública, que é a minha realidade, só vejo como possibilidade de acesso um laboratório de informática equipado com vários computadores, com uma internet paga de boa qualidade e isso temos de maneira precária. $\left(P_{I}\right)$.

Os alunos têm acesso às Redes Sociais, porém, não a utilizam com esse meio. Eles precisam compreender que essas redes podem servir de ambiente de estudo por diversas formas de materiais compartilhados $\left(\mathrm{P}_{2}\right)$. 
Praticamente todos os alunos possuem acesso às redes sociais em seus aparelhos de celular, claro aqueles que possuem o dispositivo. Quanto ao uso, se bem orientado, não vejo por que restringir $\left(P_{3}\right)$.

$\mathrm{O}$ professor $\mathrm{P}_{3}$ introduz um componente de TI que está pulverizado em nossa sociedade, que é o aparelho de celular. Em relação à presença dos recursos de TIC no ambiente escolar e com a pergunta quinze totalmente conectada com assunto aparelho celular, foi perguntado se com relação à entrada de dispositivos de TIC na escola: os alunos costumam trazer para o ambiente escolar, aparelhos tecnológicos (tablets, smartphones, notebook). Do total dos participantes, I00\% (cem por cento) relataram que os alunos levam dispositivos de TIC para a escola. Os relatos abaixo representam um resumo das respostas do público pesquisado:

Eles trazem sim, mas é proibido pelo regimento escolar. O protocolo é enviar os aparelhos tecnológicos, citados, para a direção, que entra em contato com os pais para buscarem o aparelho $\left(P_{I}\right)$.

Normalmente smartphones, porém, não utilizam com fins escolares $\left(\mathrm{P}_{2}\right)$.

Sim, trazem todos os dispositivos. Não vejo problemas em seu uso $\left(P_{3}\right)$.

Trazem mais smartphones $\left(\mathrm{P}_{4}\right)$.

Trazem com frequência o celular $\left(P_{5}\right)$.

A pergunta doze verifica a percepção dos professores quanto à velocidade que as informações veiculam "quase em tempo real" na web: qual a percepção sobre a capacidade de disseminação das informações pela 'internet'. Do total dos participantes, 30\% (trinta por cento) não apresentaram respostas que demonstrassem indícios de preocupação em relação à velocidade que as informações são disseminadas na web, enquanto 70\% (setenta por cento) relataram que a capacidade de disseminar informações pela internet é algo para ser acompanhado. Dos setenta por cento dos professores pesquisados, os relatos dos professores P8, P9, Pio representam um resumo das respostas:

A capacidade de disseminação das informações pela internet é imensurável. O que "cai" na rede é compartilhado de maneira instantânea e, na maioria das vezes, se torna uma verdade (P8).

Há uma disseminação evidente e que muitas vezes precisa ser filtrada para que realmente o que seja relevante no ambiente escolar, seja mais enfatizado e que vá ao encontro do processo ensino aprendizagem $\left(\mathrm{P}_{9}\right)$. 
Ela é extremamente rápida. Só temos que tomar cuidado com os conteúdos que repassamos e a quantidade/qualidade do que é repassado, pois se temos oportunidade de ter acesso a estas informações 24 horas, podemos ter 24 horas de ótimos conteúdos e/ou 24 horas de conteúdos que não agregam em nada (PIo).

Do total de dez professores pesquisados, I0o\% (cem por cento) relataram que proporcionam novos desafios. Os relatos dos professores $\mathrm{P}_{3}, \mathrm{P}_{7}$ e $\mathrm{P}_{2}$ representam a maioria das respostas coletadas:

Sim. Penso que o maior deles é conciliar os pensamentos literários com as formas do pensamento digital existem ganhos e perdas $\left(\mathrm{P}_{3}\right)$.

Sim. Temos que refletir sobre como usar as novas tecnologias para que os alunos se sintam dentro do contexto em que já vivem $\left(\mathrm{P}_{7}\right)$.

Sim, já não é mais possível trabalhar da mesma forma que antes. Eles se entendiam com muito mais facilidade e sabem buscar informações que lhes interessam com muita eficiência e rapidez $\left(\mathrm{P}_{2}\right)$.

A unamidade positiva das respostas apresentadas $\left(\mathrm{P}_{3}, \mathrm{P}_{7}, \mathrm{P}_{2}\right)$ trazem possíveis indícios que alguma revolução está acontecendo no ambiente escolar, tendo por pano de fundo as TICs. Não posso afirmar que revolução é essa, porém há sinais de uma profunda transformação que as escolas poderão passar. Nos relatos coletados nesta pergunta, esperei que um percentual maior de docentes tocassem no assunto de aplicar filtros nas informações acessadas por meio dos recursos de TI no ambiente escolar, o que de fato ocorreu poucas vezes, mais precisamente em apenas $20 \%$ (vinte por cento) dos relatos coletados.

Os relatos dos professores $\left(\mathrm{P}_{3}, \mathrm{P}_{4}, \mathrm{P}_{9}\right.$ e $\left.\mathrm{P}_{10}\right)$ trazem o seguinte panorama:

O acompanhamento das ferramentas de informática; atualização das TICs; equipamentos no ambiente escolar e que realmente funcionem e que sejam em quantidade suficiente para todos $\left(\mathrm{P}_{3}\right)$.

O maior desafio é a falta de preparo, capacitação e de orientação dos alunos e dos professores $\left(\mathrm{P}_{4}\right)$.

Evitar que o aluno se disperse em outros assuntos fora do conteúdo proposto, sem haver uma segurança e o controle do acesso aos meios virtuais de comunicação $\left(\mathrm{P}_{9}\right)$.

O foco em utilizar as TICs para o que realmente é ligado aos assuntos da escola (PIo). 


\section{As TICs íntimas da escola: Considerações finais}

Dentre alguns desafios apresentados pelos docentes na etapa de aplicação do questionário, no meu entendimento, o desafio maior foi mencionado poucas vezes por eles. Trata-se do desafio de fazer com que o docente assuma o papel de filtrar os conteúdos que são acessados pelos estudantes no ambiente escolar por meio dos recursos de TIC. Dentro dos relatos apresentados no questionário aplicado identifiquei que dois professores, ou seja, $20 \%$ (vinte por cento) dos pesquisados, mencionaram o fato de eles começarem a atuar no papel de filtrar as informações e de ensinar os estudantes a criarem seus próprios filtros.

Para melhor embasar a identificação do desafio apresentado, o termo conteúdo utilizado na conjuntura do papel do docente como "Filtro de conteúdo" está diretamente relacionado com a palavra "informação". Destaco, então, o conceito de informação que para Drucker (1999, p. 32) são “dados interpretados, dotados de relevância e propósito.” Já dado, para Drucker, é matéria-prima para a informação. E qual seria o filtro que os professores aplicariam nos conteúdos acessados pelos estudantes no ambiente escolar? Embora o que proponho possa permitir futuras pesquisas e reflexões em outras esferas de conhecimento sociais, culturais, comportamentais, éticas e filosóficas - seria inicialmente o docente assumir o papel de filtrar o conteúdo se ancorando em aspectos instrumentais das TICs, conforme já citado por Siqueira (2007), sendo eles: I) classificar e ordenar a informação acessada, 2) comparar, contrastar, criticar e 3) analisar as informações no contexto geral da escola.

Com a proposição do "novo" papel do professor - filtro de conteúdo - pretendi com esta pesquisa científica levantar novas reflexões de como o professor poderia aplicar filtros nos conteúdos acessados pelos estudantes na escola. Porém, entendo que na sociedade contemporânea somente o professor exercer o papel de "filtro de conteúdo" no ambiente escolar, seria algo com pouco efeito positivo para as escolas, docentes e discentes. É interessante que outros agentes que fazem parte do espaço educacional assumam, também, o papel de filtrar os conteúdos acessados pelos discentes na escola. O professor assumir o papel de "filtro" tem uma grande relevância enquanto podem existir conteúdos inverídicos, falsos e inapropriados adentrando o espaço acadêmico. A partir do interesse de cada estudante nativo digital, o professor faria um primeiro filtro nas informações acessadas e na sequência poderia ensinar os próprios alunos a construírem seus filtros, ou seja, permitir o olhar do discente nos filtros aplicados. Saliento que o docente com o "novo" papel apresentado - ser um filtro de 
conteúdo - não pode se colocar ou se tornar refém da tecnologia da informação e comunicação, mas usar o melhor possível as possibilidades positivas que as TICs podem proporcionar.

Friso que a tríade escola, professor e aluno são participantes importantes no sistema educacional, porém há um fio tenso neste contexto. A tensão está em estabelecer uma forma de inserir um componente, no caso a TIC, que agregue valor para a escola e aos processos de educação.

Em face do exposto, da pesquisa realizada, do arcabouço teórico usado nesta pesquisa, acredito que é interessante a adaptação do professor ao novo papel de ser um "filtro" de conteúdo no ambiente escolar. O "novo" papel do docente em sala de aula passa, necessariamente, pelo apoio e acompanhamento da própria instituição escolar, uma vez que seria mais um papel a ser assumido pelo docente no ambiente escolar, podendo ocasionar acúmulo de função. A ideia é a de que as TICs sejam usadas o melhor possível no ambiente escolar, não se tornando barreira ou estorvo para o aperfeiçoamento que a instituição escolar pode passar. Entendo ser pertinente que a escola e o professor repensem a forma como lidam com as questões relacionadas à tecnologia da informação e comunicação no espaço educacional. A partir das conclusões e provocações apresentadas neste trabalho de dissertação de mestrado, outras pesquisas podem ser construídas e novas conclusões constatadas.

\section{Referências bibliográficas}

AMIGUES, René. Trabalho do professor e trabalho de ensino. In: MACHADO, Anna Rachel (Org.). O ensino como trabalho: uma abordagem discursiva. Londrina: Eduel, 2004. p. 35 - 53 .

BRASIL. DECRETO n. $\mathbf{3 . 8 4 7}$, DE 25 DE JUNHO DE 200I. IPI incidente sobre os produtos que menciona, Brasília/DF, mar 2017. Disponível em: 〈http://www.imprensanacional.gov.br/mp_leis/leis_texto.asp?ld=LEI\%209887>.

Acesso em: 12 out. 2017.

BELLONI, M. L. Tecnologia e Formação de Professores: Rumo a uma Pedagogia Pós Moderna. Educação \& Sociedade, Campinas, n. 65, 1998.

CASTELLS, M. (2002). A Era da Informação: Economia, Sociedade e Cultura, Vol. I, A Sociedade em Rede. Lisboa: Fundação Calouste Gulbenkian.

COIMBRA, Cecília Maria B.. As funções da instituição escolar: análise e reflexões. Psicol. cienc. prof., Brasília, v. 9, n. 3, p. I4-I6, 1989. Disponível em 
<http://www.scielo.br/scielo.php?script=sci_arttext\&pid=SI4I498931989000300oo6\&lng=en\& $n r m=$ iso $>$. acesso em 12 Dez. 2018. http://dx.doi.org/ro.159o/SI414-98931989000300006.

DRUCKER, Peter. F. Administrando em tempos de grandes mudanças. São Paulo: PIONEIRA, I999.

ESTEVE, J.M. O mal-estar docente: a sala de aula e a saúde dos professores. São Paulo: EDUSC, 1999.

ILLICH, Ivan. Sociedades sem escolas. 7. ed. Petrópolis: Rio de Janeiro: Editora Vozes, 1985 .

LAUDON, K. C.; LAUDON, J. P. Sistemas de informação gerenciais. São Paulo: Prentice Hall, 2004.

KENSKI, Vani Moreira. Tecnologias e ensino presencial e a distância. Campinas: Papirus, 2003.

MORAN, José Manuel. Como utilizar a Internet na educação. Ci. Inf., Brasilia , v. 26, n.2, p., Mai 1997. Disponível em: <http://www.scielo.br/scielo.php?script=sci_arttext\&pid=Soroo-

19651997000200006\&lng=en\&nrm=iso .Acessoem I4 Abr. 2018. http://dx.doi.org/I.I 590/Soroo-19651997000200006.

A educação que desejamos: novos desafios e como chegar lá. Papirus: Campinas, 2007.

Novos desafios na educação: a internet na educação presencial e virtual. 200 I. Disponível em: 〈http://www.eca.usp.br $>$. Acesso em: I2 abr. 2018.

PALFREY, J.; GASSER, U. Nascidos na era digital: entendendo a primeira geração de nativos digitais. Porto Alegre: Artmed, $201 \mathrm{I}$

PINOCHET, Luis. Tecnologia da Informação e Comunicação. I. ed. Rio de Janeiro: Elsevier, 2014.

PRENSKY, Marc. Digital natives, digital immigrants part I. On the horizon, v. 9, n. 5, p. I-6, 200I.

RIANO, M. B. R. La evaluación em Educación a distancia In Revista Brasileira de Educação a Distância. Rio de Janeiro. Instituto de Pesquisas Avançadas. Ano IV, $\mathrm{N}^{\circ}$ 20 1997. P 19-35. 
SAVIANI, Dermeval. Escola é democraria. 42. ed. Campinas, SP: Autores Associados, 2012.

SIQUEIRA, Ethevaldo. Tecnologias que mudam nossa vida. São Paulo: Saraiva, 2007 SILVA, Sergio Luis da. Gestão do conhecimento: uma revisão crítica orientada pela abordagem da criação do conhecimento. Cia. Inf., Brasília , v. 33, n. 2, p. I43I5I, ago. $2004 \quad$ Disponível em 〈http://www.scielo.br/scielo.php?script=sci_arttext\&pid=Soroog652004000200015\&ln $\mathrm{g}=\mathrm{pt \& nrm}=\mathrm{iso}$. acessos em 25 maio 2018. http://dx.doi.org/I0.1590/Soroo19652004000200015 .

REIS, Homero. A tecnologia e a vulnerabilidade humana.UniCEUB, Teoria da Decisão Brasília, 2004.

TUNES, Elizabeth; TACCA, Maria Carmen V. R.; BARTHOLO JUNIOR, Roberto dos Santos. O professor e o ato de ensinar. Cad. Pesqui., São Paulo, v. 35, n. 126, p. 689-698, Dez. 2005 . Disponível em $<$ http://www.scielo.br/scielo.php?script=sci_arttext\&pid=Soroo-

$15742005000300008 \& \operatorname{lng}=$ en $\& \mathrm{nrm}=$ iso $>$. acesso em 20 Jan. 2019. http://dx.doi.org/I0.1590/Soroo-15742005000300008. 